\title{
SUPRIMENTO DE POTÁSSIO DE SOLOS DO RIO GRANDE DO SUL PARA ARROZ IRRIGADO POR ALAGAME NTO ${ }^{(1)}$
}

\author{
R. M. V.CASTILHOS ${ }^{(2)} \&$ E. J . MEURER ${ }^{(3)}$
}

\begin{abstract}
RESUMO
Cultivos em vasos têm sido utilizados para avaliar a capacidade dos solos em suprir potássio para as plantas. Com este objetivo, foi realizado um estudo com amostras de dois Planossolos, um Chernossolo e um Gleissolo do estado do Rio Grande do Sul, nos quais a cultura do arroz irrigado por alagamento não tem respondido à adu bação potássica. Os solos foram cultivados durante 50 dias, em casa de vegetação, com arroz (Oriza sativa.L. cv. BR-IRGA 409). Foram quantificados o potássio acumulado na parte aérea das plantas e os teores de K trocável e K não-trocável, extraídos dos solos por $\mathrm{NH}_{4} \mathrm{OAC} 1 \mathrm{~mol} \mathrm{L-1}$ pH 7 e por $\mathrm{HNO}_{3} 1 \mathrm{~mol} \mathrm{~L}^{-1}$ fervente, respectivamente, antes e depois do cultivo. O K acumulado pelas plantas de arroz diferiu entre os solos, decrescendo na seqüência: Gleissolo $>$ Chernossolo $>$ Planossolo $1>$ Planossolo 2. O K trocável não foi a única forma do elemento no solo que supriu o nutriente às plantas de arroz, ocorrendo contribuição de formas de K não-trocável.
\end{abstract}

Termos de indexação: $K$ trocável, $K$ não-trocável, disponi bilidade de nutrientes, análise de solo, extratores químicos, Oryza sativa.

\section{SUMMARY: POTASSIUM SUPPLY TO FLOODED RICE BY SOILS OF RIO GRANDE DO SUL, BRAZIL}

Pot experiments are being used to study the potassium supplying capacity of soils. A greenhouse experiment with this objectiveeval uated samples of two Planosols, a Chernosol and a Gleisol, whereflooded ricedid not respond to potassium fertilization. Thesoils were cropped during 50 days with rice (Oriza sativa - BR-IRGA 409). Potassium uptake by the

(1) Trabalho recebi do para publicação em outubro de 2000 e aprovado em abril de 2002.

(2) Professora do Departamento de Sol os, Universidade Federal de Pelotas - UF PEL. Caixa Postal 354, CEP $96001-970$ Pelotas (RS). E-mail: rosamvc@ufpel.tche.br

(3) Professor do Departamento de Solos, Universidade Federal do Rio Grande do Sul - UFRGS. Caixa Postal 776, CEP 90001-970 Porto Alegre (RS). Bolsista do CNPq. E-mail: egon.meurer@ufrgs.br 
plant shoot, the exchangeable and non-exchangeable soil $\mathrm{K}$, extracted by $\mathrm{NH}_{4} \mathrm{OAC} 1 \mathrm{~mol} \mathrm{~L}^{-1}$ and boiling $\mathrm{HNO}_{3} 1 \mathrm{~mol} \mathrm{~L}^{-1}$, respectively, were evaluated, before and after cropping. Potassium accumulated by the rice plants differed between the soils and decreased in the order: Gleisol > Chernosol > Planosol $1>$ Planosol 2. Exchangeable K was not the only element form in thesoil that supplied thenutrient to therice plants, sincenon-exchangeable $\mathrm{K}$ forms contributed as well.

Index terms: exchangeable K, non-exchangeable K, nutrient availability, soil analysis, chemical extractores, Oryza sativa.

\section{INTRODUÇÃO}

Estudos de calibração realizados com a cultura do arroz irrigado por alagamento, no estado do Rio Grande do Sul, mostraram que, em geral, não há relação entre o teor de potássio disponível no solo (extraído pelo método Mehlich-1) e o rendimento de grãos de arroz (Lopes, 1989; Machado \& F ranco, 1995; Simonete, 1998). Em dois Planossolos, um Chernossol o e um Gleissolo, utilizados em cultivos com arroz irrigado por alagamento, foram identificados, nos horizontes $A$ e $B$, minerais primários e secundários fontes de potássio, que, possivelmente, podem explicar a ausência de respostas à adubação potássica nesses solos (Castilhos, 1999).

Cultivos em vasos têm sido utilizados para avaliar a capacidade de suprimento de potássio de sol os para as plantas (Crisóstomo \& Castro 1970; Oliveira et al., 1971; Mielniczuk \& Selbach, 1978; Rosolem et al., 1988; Nachtigall \& Vahl, 1991a,b; Rosolem et al., 1993), constatando-se quea absorçãototal depotássio pelas plantas é maior do que o teor inicial de $\mathrm{K}$ trocável, indicando haver contribuição de outras formas de potássio, além da trocável. Nachtigall \& Vahl $(1991 a, b)$ observaram contribuição de K nãotrocável e correlação significativa entreo K extraído pelas plantas e o $\mathrm{K}$ não-trocável extraído por $\mathrm{HNO}_{3}$ 1 mol L-1, em 36 amostras de solos da região sul do RS.

Em um experimento de campo, realizado num Planossolo do RS, Simonete (1998) estimou que, mesmo considerando o efeito residual da adubação potássica do azevém na cultura do arroz irrigado por alagamento subseqüente, houve contribuição da forma não-trocável de pelo menos $29 \%$ do potássio total acumulado pelas plantas.

Também tem sido constatado, em experimentos de curta e longa duração, tanto em vasos como em condi ções de campo, queoK trocável tendea di minuir assintoticamenteatéum nível mínimo, variável com o tipo de solo, e que, concomitantemente com essa depl eção, ocorre diminuição de K não-trocável, passando o suprimento deK para as plantas a depender da liberação desta última forma (Chakravorti et al., 1987; Nachtigall \& Vahl, 1991b; M el o et al., 1995; Silva et al., 1995; Simonete, 1998; Scherer, 1998).
Por serem escassos os trabal hos que envolvem a dinâmica do $\mathrm{K}$ em solos alagados, pretendeu-se, nestetrabal ho, avaliar o suprimento deK por quatro solos utilizados no cultivo de arroz irrigado por alagamento e quantificar a contribuição das formas de potássio na absor ção deste nutriente por plantas de arroz.

\section{MATE RIAL E MÉTODOS}

O experimento foi real izado em casa de vegetação e nos laboratórios do Departamento de Solos da Faculdade de Agronomia da Universidade Federal do Rio Grande do Sul (UFRGS), no município de Porto Al egre (RS), no período de novembro de 1995 a dezembro de 1996.

Amostras do horizonte superficial $(0-20 \mathrm{~cm})$ de dois Planossolos (Planossolo 1 e Planossolo 2), um Chernossolo e um Gleissolo, foram coletadas no campo, secas ao ar e tamisadas em peneiras com malha de $4 \mathrm{~mm}$ de abertura, para ocultivo em vasos, e com mal ha de $2 \mathrm{~mm}$ de abertura, para as análises físicas e químicas (Quadros 1 e 2).

Antes do cultivo, foi feita a cal agem dos sol os para elevar o pH a 6,0, com uma mistura de $\mathrm{CaCO}_{3}$ e $\mathrm{MgCO}_{3}$ (na proporção molar de 3:1), de acordo com a recomendação de calagem pelo método do SMP (CFS-RSSC, 1995). N esta ocasião, efetuou-se uma adubação fosfatada, com superfosfato triplo, nas doses de $250 \mathrm{mg} \mathrm{dm}^{-3}$ deP, no Planossolo 1, Gleissolo e Chernossolo, e na dose de $150 \mathrm{mg} \mathrm{dm}^{-3}$ de $\mathrm{P}$, no Planossolo 2, tendo-se considerado na escol ha das doses os testes prel iminares de adsorção deP nesses solos. Nos quatro solos, foi aplicada uma adubação nitrogenada com sulfato de amônio na dose de $100 \mathrm{mg} \mathrm{dm}^{-3}$ deN; nãoseaplicaram micronutrientes aos solos.

Em seguida, os sol os foram umedeci dos com água destilada, até atingir o grau de umidade correspondente à capacidade de campo (água retida à tensão de 0,3 MPa), eincubados, em sacos plásticos, por um período de 15 dias. O cultivo foi realizado em casa de vegetação, em vasos com capacidade de $9,0 \mathrm{~L}^{-1}$, onde foram colocados $6,0 \mathrm{dm}^{3}$ de solo. O delineamento experimental usado foi o de blocos ao acaso, com quatro repetições. Semearam-se 
Quadro 1. Material de origem, minerais fontes de K, município de coleta, densidade, classe textural e composição granulométrica dos solos

\begin{tabular}{lcccc}
\hline \multicolumn{1}{c}{ Característica } & Planossolo $\mathbf{1}$ & Planossolo 2 & Chernossolo & Gleissolo \\
\hline Material de origem & Sedimento granito & Sedimento costeiros & Sedimento basalto & Sedimentos aluviais \\
Minerais fontes de K(1) & $\mathrm{F}, \mathrm{m}, \mathrm{me}$ & $\mathrm{F}, \mathrm{m}, \mathrm{me}$ & $\mathrm{F}, \mathrm{m}, \mathrm{me}$ & $\mathrm{F}, \mathrm{m}, \mathrm{me}$ \\
Município de coleta (RS) & Pelotas & Palmares & Uruguaiana & Santa Maria \\
Densidade kg dm-3 & 1,057 & 1,315 & 0,887 & 0,905 \\
Classe textural & Franco & Areia & Franco-argiloso & Franco-argiloso \\
Areia g kg-1 & 490 & 910 & 320 & 260 \\
Silte g kg-1 & 330 & 30 & 310 & 360 \\
Argila g kg-1 & 180 & 60 & 370 & 380 \\
\hline
\end{tabular}

(1) $\mathrm{F}=$ feldspato; $\mathrm{m}=$ mica; $\mathrm{me}=$ mica-esmectita (Castilhos, 1999).

Quadro 2. Atributos ${ }^{(1)}$ das amostras do horizonte A dos solos coletadas no campo antes do cultivo

\begin{tabular}{|c|c|c|c|c|c|c|c|c|}
\hline \multirow{2}{*}{ Solo } & \multirow{2}{*}{ pH $\mathrm{H}_{2} \mathrm{O}$} & \multirow{2}{*}{ Matéria orgânica } & \multirow{2}{*}{ P extraível(1) } & \multirow{2}{*}{ K disponível(1) } & \multicolumn{3}{|c|}{ Cátion trocável } & \multirow{2}{*}{ CTC efetiva } \\
\hline & & & & & $\mathrm{Al}^{3+}$ & $\mathrm{Ca}^{2+}$ & $\mathbf{M g}^{2+}$ & \\
\hline & & $\mathrm{g} \mathrm{kg}^{-1}$ & mg k & $\mathrm{kg}^{-1}$ & $\longrightarrow$ & $\mathrm{cmc}$ & $\mathrm{c} \mathrm{kg}^{-1}$ & - \\
\hline Planossolo 1 & 5,1 & 21 & 8,0 & 31 & 0,3 & 2,8 & 1,4 & 4,9 \\
\hline Planossolo 2 & 6,0 & 13 & 11,0 & 12 & 0,0 & 1,3 & 1,0 & 2,6 \\
\hline Chernossolo & 5,4 & 37 & 3,0 & 41 & 0,1 & 14,5 & 5,7 & 20,6 \\
\hline Gleissolo & 4,9 & 26 & 3,0 & 44 & 1,9 & 3,9 & 1,6 & 7,6 \\
\hline
\end{tabular}

(1) Análises de acordo com os métodos descritos por Tedesco et al. (1995); K trocável extraído por Mehlich-1.

50 sementes dearroz (cultivar BR-IRGA 409) e, após a emergência das plantas, efetuou-se o desbaste para 20 plantas por vaso.

Os vasos foram submetidos à condição de alagamento, dos 14 dias após a semeadura até o término do experimento, aos 50 dias, mantendo-se sobre a superfície dos sol os uma lâmina de água de $5 \mathrm{~cm}$ de espessura. Duas aplicações de $20 \mathrm{mg} \mathrm{dm}^{-3}$ de N, na forma de solução de uréia, foram feitas aos 27 e 35 dias do início do cultivo. De cada vaso, col etou-sea parte aérea das plantas, que foi seca em estufa a $60^{\circ} \mathrm{C}$ por 72 horas, determinando-se, então, a massa seca das mesmas. Nesta ocasião, foram col etadas subamostras dos solos, de $5 \mathrm{em} 5 \mathrm{~cm}$, em toda a profundi dade dos vasos, com vistas em compor uma amostra média de cada vaso, para as análises químicas. Os resultados foram submetidos à análise da variância, e as médias ao teste de Duncan a $5 \%$.

$\mathrm{Na}$ parte aérea das plantas, após secas, moídas e peneiradas (20 malhas por pol egada), determinouse o teor de K, conforme método descrito em Tedesco et al. (1995). Para calcular as quantidades de K retiradas pelo cultivo, tomou-se por base a quantidade de matéria seca produzida e sua concentração em $\mathrm{K}$. A quantidade de $\mathrm{K}$ acumulado nas raízes foi estimada a partir de dados obtidos por Castilhos et al. (2001), que, analisando plantas de arroz crescendo em solução nutritiva, em casa de vegetação, durante 56 dias, com suprimento adequado de potássio, encontraram $20 \%$ do K absorvido pela planta acumulado nas raízes. Tal procedimento foi adotado, por ser problemática a determinação do teor de $\mathrm{K}$ nas raízes de plantas crescendo em solos, uma vez que, para preparar as raízes para as análises químicas, é necessário laválas com água destilada, para separar as partículas de solo aderidas às raízes. Como $\mathrm{K}$ não forma compostos orgânicos dentro da planta, no processo de lavagem das raízes, há remoção da maior parte do K nelas acumulado.

Amostras dos sol os feitas antes edepois do cultivo, após secagem e tamisagem em peneira de $2 \mathrm{~mm}$, foram submetidas às seguintes análises: (a) extração do K trocável com $\mathrm{NH}_{4} \mathrm{OAc} 1$ mol L-1 pH 7,0 (relação sol o/extrator de 1:10, agitação por 1 h ecentrifugação por $15 \mathrm{~min}$ a $2.000 \mathrm{rpm}$ ); (b) determinação do $\mathrm{K}$ extraível com $\mathrm{HNO}_{3} 1 \mathrm{~mol} \mathrm{~L}-1$ fervente $\left(\mathrm{K}-\mathrm{HNO}_{3}\right)$, conformePratt (1973); (c) K total, extraído por ácido fluorídrico (Pratt, 1973). Os teores de K nos extratos foram determinados por fotometria de chama. 
Considerando que o $\mathrm{HNO}_{3} 1 \mathrm{~mol} \mathrm{~L}^{-1}$ extrai formas "K trocável"e "K não-trocável", considerou-se, neste trabalho, como sendo a fração "K não-trocável" a quantidade de $\mathrm{K}$ extraída pelo $\mathrm{NHO}_{3} 1 \mathrm{~mol} \mathrm{~L}^{-1}$ subtraída da fração extraída pel o $\mathrm{NH}_{4} \mathrm{OAc} 1 \mathrm{~mol} \mathrm{~L}-1$ $\mathrm{pH} 7$.

\section{RESULTADOS E DISCUSSÃO}

No quadro 3, encontram-se os teores de $\mathrm{K}$ total, K não-trocável (Knt) e de K trocável (Kt) extraídas das amostras dos solos, antes e depois do cultivo das plantas de arroz. Os sol os contêm teores significativamente diferentes de K total, que variam de 1.935 a $5.571 \mathrm{mg} \mathrm{kg}^{-1}$ de $K$, decrescendo na seqüência: Planossolo $1>$ Gleissolo $>$ Chernossolo > Planossolo 2. São teores semelhantes aos relatados por Nachtigall \& Vahl (1991a), para solos derivados do mesmo material de origem (sedimentos costeiros, sedimentos aluviais e sedimentos do granito). A presença de fel dspatos e micas, nas frações areia e silte, e o predomínio de minerais interestratificados mica-esmectitas, esmectita com hidróxi-entrecamadas (EHE) e esmectitas, na fração argila (Castilhos, 1999), justificam os valores de K total encontrados nesses solos.

Os teores de potássio extraídos pelo $\mathrm{NH}_{4} \mathrm{OAc}$, reconhecidos como "K trocável" na literatura, também diferiram significativamente entre os sol os (Quadro 3), apresentando uma variação de 12 a $59 \mathrm{mg} \mathrm{kg}^{-1}$ de $\mathrm{K}$, o mesmo ocorrendo com os teores extraídos pelo $\mathrm{HNO}_{3}$, que variaram de $25 \mathrm{a} 88 \mathrm{mg} \mathrm{kg}^{-1}$. A pós o cultivo, os teores deK (trocável enão-trocável) detectados nos quatro solos por esses extratores decresceram nos quatro solos, com diferenças significativas entre eles.

O K acumulado nas plantas de arroz (Quadro 4) indicam que os quatro sol os apresentaram diferentes capacidade de suprir o K. No Planossolo 1, no Chernossolo e no Gleissolo, as quantidades acumuladas variaram de 248,8 a 273,9 mg deK por vaso; no Planossolo 2, a quantidade acumulada nas plantas foi baixa, de $96,2 \mathrm{mg}$ de $\mathrm{K}$ por vaso. Neste solo, que apresentou o menor teor de $\mathrm{K}$ total e menores teores de K trocável e K não-trocável, observaram-se sintomas visuais de deficiência de $K$ nas plantas no término do experimento.

Supondo que o método utilizado para avaliar a forma "K trocável" ( $\mathrm{NH}_{4} \mathrm{OAc} 1 \mathrm{~mol} \mathrm{L-1} \mathrm{pH}$ 7) foi adequado e que as diferenças nos teores de $K$ trocável antes e depois do cultivo $(\Delta \mathrm{K} t)$ correspondem às quantidades que foram acumuladas nas plantas, pode-se deduzir que houve contribuição de $\mathrm{K}$ sob outras formas no solo ("K não-trocável") no suprimento do nutriente às plantas, desde que os decréscimos do $\mathrm{K}$ trocável $(\Delta \mathrm{K} \mathrm{t})$ nos quatros solos são inferiores às quantidades removidas pelas plantas (Quadro 4). As quantidades provenientes de formas de K nãotrocável teriam sido de $128,3 \mathrm{mg}$ de $\mathrm{K}$ por vaso, no Planossolo 1; de 48,1, no Planossolo 2; de 142,7, no Chernossolo, e de 185,3, no Gleissolo. O decréscimo do K não-trocável dos solos ( $\Delta \mathrm{KnT}$ ) foi menor (no Planossolo 1 e no Gleissolo) ou maior (noPlanossolo 2 e no Chernossolo) (Quadro 4) do que as quantidades absorvidas pelas plantas que teriam sido supridas por forma de K não-trocável. Estes dados podem indicar que o acetato de amônio ou o ácido nítrico, ou ambos os extratores, não avaliam e, ou, refletem, adequadamente, a dinâmica do K no solo.

Fernandes et al. (1993), estudando a nutrição de soja e formas de $\mathrm{K}$ num Latossolo, constataram que o K disponível à soja foi também proveniente do $\mathrm{K}$ extraído pelo $\mathrm{HNO}_{3} 1 \mathrm{~mol} \mathrm{~L}^{-1}$ fervente, considerado como trocável e não-trocável. Esses autores concluíram que a classificação do $\mathrm{K}$ do solo em trocável e não-trocável não foi adequada para explicar a nutrição da soja no Latossolo. Sugeriram, ainda, que formas de $\mathrm{K}$ não extraídas pelo $\mathrm{HNO}_{3}$

Quadro 3. Teores de K total, K não-trocável (Knt) e K trocável (Kt) nos solos, antes e depois do cultivo do arroz por 50 dias

\begin{tabular}{|c|c|c|c|c|c|}
\hline \multirow{2}{*}{ Solo } & \multicolumn{3}{|c|}{ Antes do cultivo } & \multicolumn{2}{|c|}{ Após o cultivo } \\
\hline & K-total & Knt & $\mathbf{K t}(\mathbf{1})$ & Knt & $\mathbf{K t}$ \\
\hline & & & $\mathrm{g} \mathrm{kg}^{-1}$ & & 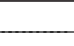 \\
\hline Planossolo 1 & $5.571 \mathrm{a}$ & $49 \mathrm{c}$ & $35 c$ & $34 \mathrm{c}$ & $16 \mathrm{c}$ \\
\hline Planossolo 2 & $1.935 \mathrm{c}$ & $25 d$ & $12 \mathrm{~d}$ & $18 \mathrm{~d}$ & $6 \mathrm{~d}$ \\
\hline Chernossolo & $2.074 \mathrm{c}$ & $88 \mathrm{a}$ & 59 a & $57 \mathrm{a}$ & $39 a$ \\
\hline Gleissolo & $5.248 \mathrm{~b}$ & $68 \mathrm{~b}$ & $53 \mathrm{~b}$ & $48 \mathrm{~b}$ & $36 \mathrm{~b}$ \\
\hline Média & 3.614 & 57 & 40 & 39 & 24 \\
\hline
\end{tabular}

(1) Extração com $\mathrm{NH}_{4} \mathrm{OAc} 1$ mol L-1 $\mathrm{pH} \mathrm{7,0.}$

Médias seguidas da mesma letra, na coluna, não diferem pelo teste de Duncan a $5 \%$. 
Quadro 4. Matéria seca, K acumulado nas plantas de arroz (K-planta) e quantidades de K não-trocável (Knt) e de K trocável (Kt) nos vasos, antes e depois do cultivo do arroz por 50 dias

\begin{tabular}{|c|c|c|c|c|c|c|c|c|}
\hline \multirow{2}{*}{ Solo } & \multirow{2}{*}{ Matéria seca } & \multirow{2}{*}{ K - planta } & \multicolumn{2}{|c|}{ Knt } & \multirow{2}{*}{$\Delta K n^{(1)}$} & \multicolumn{2}{|c|}{ Kt } & \multirow{2}{*}{$\Delta K \mathbf{t}^{(2)}$} \\
\hline & & & Antes & Após & & Antes & Após & \\
\hline & g vaso-1 & & & -1 & vaso $^{-1}$ & & & - \\
\hline Planossolo 1 & $26,1 \mathrm{a}$ & $199,0 \mathrm{~b}$ & 312,2 & 215,1 & $97,1 \mathrm{~b}$ & 218,9 & 98,3 & $120,5 \mathrm{a}$ \\
\hline Planossolo 2 & $11,9 \mathrm{c}$ & $77,0 \mathrm{c}$ & 195,6 & 138,8 & $56,8 \mathrm{c}$ & 97,0 & 48,9 & $48,1 d$ \\
\hline Chernossolo & $23,9 \mathrm{~b}$ & $201,0 a b$ & 466,3 & 303,0 & $163,2 \mathrm{a}$ & 314,8 & 206,3 & $108,5 \mathrm{~b}$ \\
\hline Gleissolo & $26,2 \mathrm{a}$ & $219,1 \mathrm{a}$ & 368,6 & 262,0 & $106,5 \mathrm{~b}$ & 286,5 & 197,9 & $88,6 \mathrm{c}$ \\
\hline
\end{tabular}

(1) $\Delta$ Knt e $\Delta$ Kt indicam, respectivamente, a diferença das quantidades do K não-trocável e do K trocável, antes e depois do cultivo.

(2) Médias seguidas da mesma letra, na coluna, não diferem pelo teste de Duncan a $5 \%$.

podem contribuir para o suprimento de $\mathrm{K}$ nas plantas ou que existam formas de $\mathrm{K}$ no solo não consideradas na descrição clássica de seu comportamento no solo.

Segundo Rosolem et al . (1993), Silva et al . (1995) e Kaminski et al. (1996), o K extraído pelo $\mathrm{HNO}_{3}$ $1 \mathrm{~mol} \mathrm{~L}^{-1}$ fervente não explicou, de modo satisfatório, a dinâmica da forma $\mathrm{K}$ não-trocável do solo. Meurer et al. (1996), em estudo sobre formas de K em solos do Rio Grande do Sul, comentaram que $\mathrm{O} \mathrm{HNO}_{3}$ $1 \mathrm{~mol} \mathrm{~L}^{-1}$ fervente, utilizado para quantificar 0 K não-trocável nesses solos, apresentava capacidade para dissolver o K da estrutura dos minerais, similarmente como outros ácidos fortes, o que pode resultar numa superestimação dos teores de K nãotrocável nosolo. Verma et al. (1994), comparandoas análises de 13 solos cultivados com arroz na Í ndia, mantidos em laboratório, por um período de 10 semanas, secos ao ar e alagados, constataram que, pelo alagamento, oK solúvel em água e o K trocável ( $\mathrm{K}-\mathrm{NH}_{4} \mathrm{OAcl} \mathrm{mol} \mathrm{L}^{-1} \mathrm{pH} 7,0$ ) aumentaram, em média, cerca de 155 e $39 \%$, respectivamente. Contrariamente, as quantidades de $\mathrm{K}$ não-trocável $\left(\mathrm{K}-\mathrm{HNO}_{3}\right.$ $1 \mathrm{~mol} \mathrm{~L}^{-1}$ ) e deK estrutural ( $\mathrm{K}$ total $-\mathrm{KHNO}_{3} 1 \mathrm{~mol} \mathrm{~L}^{-1}$ ) diminuíram, evidenciando o estabel ecimento de um novo equilíbrio entre as formas de K.

Os resultados obtidos no presente estudo indicaram que oK trocável não foi a única forma do elemento no solo que supriu o nutriente às plantas dearroz, ocorrendo contribuição de formas deK nãotrocável. I sto pode explicar a falta de resposta ao arroz alagado a essenutriente, observada em experimentos de campo efetuados nestes solos (Lopes, 1989; Machado \& Franco, 1995; Simonete, 1998). Os resultados evidenciam, também, que o índice K trocável, utilizado isoladamente, nãoé eficaz para avaliar a disponibilidade do $\mathrm{K}$ em solos alagados, $\mathrm{O}$ mesmo acontecendo, com o $\mathrm{HNO}_{3} 1 \mathrm{~mol} \mathrm{~L}^{-1}$ fervente, para estimar a contribuição às plantas de forma nãotrocáveis do el emento.
Neste trabalho, as determinações do Kt e do Knt foram realizadas em amostras secas, col etadas antes e depois do cultivo do arroz, e as condi ções de redução do solo, pel o alagamento, podem, ou não, ter alterado o equilíbrio do $\mathrm{K}$ no solo. Os resultados deste trabalho revelam a necessidade de mais estudos sobre a dinâmica de equilíbrio de $\mathrm{K}$ em solos al agados, bem como a necessi dade de testar métodos ou procedimentos mais adequados e eficazes para avaliar a disponibilidade de K no sol o para a cultura do arroz irrigado por inundação.

\section{CONCLUSÕES}

1. Os solos diferiram quanto à sua capacidade de suprir K para as plantas de arroz irrigado por alagamento, avaliada pela quantidade do nutriente acumuladonas plantas. A capacidade desuprimento doK decresceu na seqüência: Gleissol o >Chernossolo >Planossolo 1 > Planossolo 2 .

2. O K trocável não foi a única forma de elemento no solo que supriu o nutriente às plantas de arroz, ocorrendo contribuição deformas deK não-trocável.

\section{LITERATURA CITADA}

CASTILHOS, R.M.V. Suprimento de potássio em solos cultivados com arroz irrigado e sua relação com mineralogia, formas e cinética de liberação. Porto Alegre, Universidade Federal do Rio Grande do Sul, 1999. 175p. (Tese de Doutorado)

CASTILHOS, R.M.V.; VAHL, L.C. \& MEURER, E.J . Efeito do potássio e sódio no crescimento do arroz. In: CONGRESSO BRASILEIRO DE ARROZ IRRIGADO, 2.; REUNIÃO DA CULTURA DO ARROZIRRIGADO, 24., PortoAlegre, 2001. Anais. PortoAlegre, I nstituto Riograndense do Arroz, 2001. v.1. p.290-292. 
CHAKRAVORTI, S.P.; BIDDAPPA, C.C. \& PATNAIK, S. Dynamics of potassium in submerged soils growing rice (Oryza sativa L.) 2. Change in forms of soil potassium and the relationship with its uptake by rice under continuous cropping. J. Potassium Res., 3:98-106, 1987.

COMISSÃO DE FERTILIDADE DO SOLO - CFSRSISC. Recomendações de adubação e calagem para os estados do Rio Grande do sul e Santa Catarina. 3.ed. Passo Fundo, Sociedade Brasileira de Ciência do Solo - Núcleo Regional Sul/EMBRAPA/CNPT, 1995. 224p.

CRISÓSTOMO, L.A. \& CASTRO, A.F. Poder de suprimento de K de solos da zona fisiográfica de Baturité, Ceará, Brasil. Turrialba, 20:425-433, 1970.

FERNANDES, D.M.; ROSSETO, C.A.V.; ISHIMURA, I. \& ROSOLEM, C.A. Nutrição da soja e formas de potássio no solo em função de cultivares e adubação potássica. R. Bras. Ci. Solo, 17:405-410, 1993.

KAMINSKI,J .; REINHEIMER, D.S.;BARTZ, H.R.; XAVIER, F.M. \& VEDUIN, J.V.R. Dinâmica da disponibilidade de potássio em solo arenoso. In: CONGRESSO LATINO AMERICANO DE CIÊNCIA DO SOLO, SOLO-SUELO, 8., Águas de Lindóia, 1996. Anais. Campinas, Sociedade Brasileira de Ciência do Solo, 1996. CD-ROM

LOPES, S.I.G. Calibração de análise de solo para arroz irrigado. In: REUNIÃO DA CULTURA DO ARROZIRRIGADO, 18., Porto Alegre, 1989. Anais. Porto Alegre, Instituto Riograndense do Arroz, 1989. p.191-201.

MACHADO , M.O. \& FRANCO,J .C.B. Parcelamento da adubação potássica em arroz pré-germinado, no solo Pelotas (Planossolo). In: REUNIÃO DA CULTURA DO ARROZ IRRIGADO, 21., Porto Alegre, 1975. Anais. Porto Alegre, Insituto Riograndense do Arroz, 1995. p.177-180.

MELO, V.F.; COSTA, L.M.; BARROS, N.F.; FONTES, M.P.F. \& NOVAIS, R.F. Reserva mineral e caracterização mineralógica dealguns sol os do Rio Grande do Sul. R. Bras. Ci. Solo, 19:159-164, 1995.

MEURER, E.J .; KÄMPF, N. \& ANGHINONI, I. Fontes potenciais de potássio em alguns solos do Rio Grande do Sul. R. Bras. Ci. Solo, 20:41-47, 1996.

MIELNICZUK, J . \& SELBACH, P.A. Capacidade de suprimento de potássio de seis solos do Rio Grande do Sul. R. Bras. Ci. Solo, 2:115-120, 1978.
NACHTIGALL, G.R. \& VAHL, L.C. Capacidade de suprimento de potássio dos solos da região sul do Rio Grande do Sul. R. Bras. Ci. Solo, 15:37-42, 1991a.

NACHTIGALL, G.R. \& VAHL, L.C. Dinâmica de liberação de potássio dos solos da região sul do Rio Grande do Sul. R. Bras. Ci. Solo, 15:43-47, 1991b.

OLIVEIRA, V.; LUDWICK, A.E. \& BEATTY, M.T. Potassium removed from some Southern Brazilian soils by exhaustive cropping and chemical extraction methods. Soil Sci. Soc. Am. Proc., 35:763-767, 1971.

PRATT, P.F. Potassium. In: BLACK, C.A., ed. Methods of soil analysis. Madison, America Society of Agronomy, 1973. v.1. p.1022-1032.

ROSOLEM, C.A.; MACHADO, J.R. \& RIBEIRO, D.B.O. Formas de potássio no sol o e nutrição potássica da soja. R. Bras. Ci. Solo, 12:121-125, 1988.

ROSOLEM, C.C.A.; BESSA, A. \& PEREIRA, H.F.M. Dinâmica do potássio no solo e nutrição potássica da soja. Pesq. Agropec. Bras., 28:1045-1054, 1993.

SCHERER, E.E. Resposta da soja à adubação potássica em Latossolo Húmico distrófico num período de doze anos. R. Bras. Ci. Solo, 22:49-55, 1998.

SILVA, D.N.; MEURER, E.J .; KÄMPF, N. \& BORKERT, C.M. Mineralogia e formas de potássio em dois Latossolos do estado do Paraná e suas relações com a disponibilidade para as plantas. R. Bras. Ci. Solo, 19:433-439, 1995.

SIMONETE, M.A. Efeito residual da adubação potássica do azevém sobre o arroz subseqüente em plantio direto. Pelotas, Universidade Federal de Pelotas 1998. 40p. (Tese de Mestrado)

TEDESCO, M.J .; GIANELLO, C.; BISSANI, C.A.; BOHNEN, H \& VOLKWEISS, S.J. Análise de solos, plantas e outros materiais. 2.ed. Porto Alegre, Universidade Federal do Rio Grande do Sul, 1995. 174p. (Boletim Técnico, 5)

VERMA, T.S.; BHAGAT, R.M. \& KAMLA, K. Evaluation of chemical methods for the determination of available potassium in waterlogged soils; (I) Potassium availability indices in relation to potassium fractions. J . Potasium Res., 100:12-22, 1994. 